\title{
Announcement: Teacher Preparation Book
}

Contributions are solicited for a forthcoming book on the preparation and professional development of teachers of physics and physical science. The book, to be published jointly by the American Physical Society and American Association of Physics Teachers, will include new reports reflecting cutting-edge research and practice, as well as reprints of previously published seminal papers. Printed copies will be distributed to chairs of all physics departments in the United States. The book will also be freely available online.

Papers submitted for publication should focus specifically on physics and physical-science education research, or on research-based instruction and curriculum development, directed at pre-service or in-service teachers of physics and physical science. The primary intended audience consists of physics department chairs and faculty members at physics-degree-granting institutions in the United States.

It is intended that papers included in the book will also be published either in the American Journal of Physics (AJP) or in Physical Review Special Topics - Physics Education Research (PRST-PER). Prior to submitting any manuscript, prospective authors should submit an outline/ prospectus to the book editors. Pre-submission discussion with the book editors is recommended. A detailed set of editorial guidelines and procedures is available online at the PTEC website (www.PTEC.org). Tentative deadline dates: Prospectus submission by March 1, 2008; manuscript submission by August 1, 2008.

Published 11 September 2007

DOI: 10.1103/PhysRevSTPER.3.020103

PACS number(s): 01.10.Cr, 01.40.J-, 01.40.Fk 